Report No. FE-MIT-92111-10

\title{
Conversion of Light Hydrocarbon Gases to Metal Carbides for Production of Liquid Fuels and Chemicals
}

\section{Quarterly Technical Status Report for the Period January 1 - March 31, 1995 DOE/PETC-MIT Contract No. DE-AC22-92PC92111}

\author{
Alexander F. Diaz, Anthony J. Modestino, Jason D. Pride, \\ Jack B. Howard, Jefferson W. Tester and William A. Peters \\ Energy Laboratory and Dept. of Chemical Engineering \\ MIT, Cambridge, MA 02139
}

\section{DISCLAIMER}

This report was prepared as an account of work sponsored by an agency of the United States Government. Neither the United States Government, nor any agency thereof, nor any of their employees, makes warranty, express or implied, or assumes any legal liability or responsibility for the accuracy, completeness, or usefulness of any information, apparatus, product, or process disclosed, or represents that its use would not infringe privately owned rights. Reference herein to any specific commercial product, process, or service by trade name, trade mark, manufacturer, or otherwise, does not necessarily constitute or imply its endorsement, recommendation, or favoring by the United States Government or any agency thereof. The views and opinions of the authors expressed herein do not necessarily state or reflect those of the United States Government or any agency thereof.

Submitted in Final Form: May 1995

Pittsburgh Energy Technology Center

Attention: Dr. Arun C. Bose

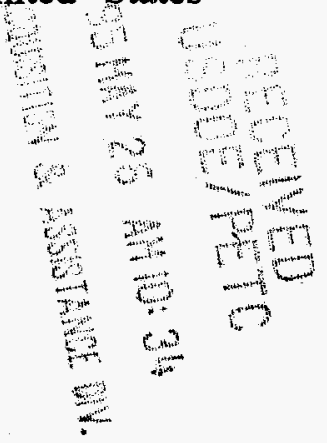

Date Submitted: May 1995

U.S. DOE Patent Clearance is not required prior to the publication of this document. 


\section{DISCLAIMER}

Portions of this document may be illegible in electronic image products. Images are produced from the best available original document. 


\begin{abstract}
The methane plasma stabilization problem was resolved with the reconfiguration of the DC power supply to give a higher open circuit voltage to enable operation of the arc at higher voltage levels and with the installation of a solenoid around the plasma reactor to magnetically rotate the arc. Cathode tip erosion problems were encountered with the $1 / 4$-inch graphite and tungsten tips which necessitated a redesign of the plasma reactor. The new plasma reactor consists of an enlarged 3/4-inch O.D. graphite tip to reduce current density and a 1-inch I.D. graphite anode. Products from $\mathrm{MgO} / \mathrm{CH}_{4}$ scoping runs in the redesigned reactor under conditions of excess $\mathrm{MgO}$ gave strong indications that a breakthrough has finally been achieved i.e. that synthesis of magnesium carbides from $\mathrm{MgO}$ and methane in the arc discharge reactor has been demonstrated. Significant quantities of hydrocarbons, primarily $\mathrm{C}_{3} \mathrm{H}_{4}$ and $\mathrm{C}_{2} \mathrm{H}_{2}$, were detected in the headspace above hydrolyzed solid samples by GC analysis. In one run, solids glowed upon exposure to the atmosphere, strongly suggesting carbide reaction with moisture in the air, exothermically forming acetylenes which ignited instantaneously in the presence of oxygen and elevated temperatures arising from localized heat-up of the specimens.
\end{abstract}




\section{Progress on Task 1: Industrial Chemistry and Applied Kinetics of Light Hydrocarbon Gas Conversion to Metal Carbides, Hydrogen and Carbon Monoxide}

In this Section, the highlights of the progress on Task 1 are discussed. By way of introduction, a recap of the work in the previous quarter is first reported in Section 1.1. Section 1.2 presents a discussion of the work in the current quarter.

\subsection{Summary of Work in Previous Reporting Period (October 1 - December 31, 1994)}

Scoping runs with up to $0.125 \mathrm{cfm}$ methane in $1 \mathrm{cfm}$ (ambient temperature) of argon and $12 \mathrm{~g} / \mathrm{min}$ of $\mathrm{MgO}$ were performed in October using a graphite anode and tungsten cathode in the new plasma reactor. A GC analysis of the gas sample from the cooling chamber and of the head space gas above the hydrolyzed solid sample revealed the presence of $\mathrm{C}_{3} \mathrm{H}_{4}$ and $\mathrm{C}_{2} \mathrm{H}_{2}$, which suggests the formation of magnesium carbide. However, a similar run performed with $\mathrm{MgO}$ feeding into a pure argon plasma gave similar results, indicating possible reaction of the graphite electrode with the $\mathrm{MgO}$ to form carbides and/or direct formation of $\mathrm{C}_{3} \mathrm{H}_{4}$ and $\mathrm{C}_{2} \mathrm{H}_{2}$ in the arc. A $\mathrm{GC}$ analysis of the gas sample taken from the cooling chamber from a run in an argon plasma without $\mathrm{MgO}$ feeding did not yield any $\mathrm{C}_{3} \mathrm{H}_{4}$ and $\mathrm{C}_{2} \mathrm{H}_{2}$, suggesting that the $\mathrm{MgO}$ powder is hydrated and is a probable hydrogen source.

\subsection{Progress during Current Reporting Period}

In the current reporting period, methane plasma stabilization was achieved and scoping runs with methane and magnesium oxide were performed. The results of the scoping runs indicate that synthesis of magnesium carbides from $\mathrm{MgO}$ and methane in the arc discharge reactor was achieved. Section 1.2.1 describes the solution of the methane plasma stabilization problem and Section 1.2.2 discusses the results of the $\mathrm{CH}_{4} / \mathrm{MgO}$ scoping runs. Section 1.2.3 describes the experimental apparatus upgrading needed in preparation for performing systematic studies of carbide formation.

\subsubsection{Methane Plasma Stabilization}

The theoretical bases for the solution of the methane plasma stabilization problem are first discussed in Section 1.2.1.1, followed by a chronological listing in Section 1.2.1.2 of specific troubleshooting actions performed.

\subsubsection{Theoretical Considerations}

Thus far, the main obstacle to performing a methane/MgO scoping run has been the instability of the methane plasma. Two approaches were taken to address this issue. First, the power supply was reconfigured to give a higher open circuit voltage and thus enable operation of the arc at higher voltage levels. The electrical field strength which provides the main source of energy to ionize a gas is higher for molecular gases like methane than that for atomic gases like argon. A second approach is to magnetically rotate the arc by installing a solenoid around the 
plasma reactor. This is expected to stabilize the arc and may also promote better plasma-solid mixing.

Molecular gases require a higher electrical field strength for sustaining an arc discharge than atomic gases because of the accompanying chemical processes of dissociation, ionization and recombination. In such a gas, the density of the molecules decreases and that of atoms increases with rising temperature. Density gradients arise, causing diffusion currents whereby pairs of atoms diffuse into cooler regions to recombine while molecules migrate into warm regions to dissociate (Gross et al., 1969). Energy is liberated in the recombination process in the cool region while energy is absorbed in the dissociation process in the warm region. This process of atomic diffusion and recombination causes significant heat losses from the arc. Consequently, more energy is needed to sustain a plasma fed by molecular rather than only by atomic gases like argon. Thus, in the present case, methane, despite its lower ionization potential relative to argon, requires a higher arc operating voltage.

In Kim's experiments $(1977,1979)$, arc voltages for a methane plasma ranged from 60 to 110 volts for flowrates of $16.0-17.3 \mathrm{l} / \mathrm{min}$ and from 65 to 115 volts for flowrates of $30.0-35.8$ $1 / \mathrm{min}$. He found his arc to be moderately stable at gas flowrates of $16.0-17.3 \mathrm{l} / \mathrm{min}$ and at arc voltages less than 75 volts, but mostly unstable at higher gas flowrates. The instability was presumably due to limitations on the output voltage of his power supply. Kim used a d.c. power supply with an open circuit voltage (OCV) of 160 volts and found that his arc became unstable when the voltage exceeded half the open circuit voltage. Instability at high gas flowrates is not unexpected because increasing the gas flow velocity requires a higher enthalpy input and a higher electric field strength in order to compensate for increased energy losses due to the higher convective cooling of the arc column. Furthermore, a higher gas flowrate results in elongation of the arc column which also requires an increased voltage to sustain the same field strength. This is consistent with Blanchet's (1963) ability to sustain a methane plasma between a continuously-fed graphite anode and a water-cooled brass cathode at a much lower flowrate (1.5 $1 / \mathrm{min}$ ) at voltages of $40-80$ volts.

The second approach to plasma stabilization involves applying a magnetic field perpendicular to the arc current which induces in the charged particles a velocity component perpendicular to their original direction of travel. Consequently, the path of charged particles moving in a plane perpendicular to the magnetic field will curve. However, the mean free path of the particles remains practically unaltered. One effect is that the electric conductivity of the plasma becomes more anisotropic under these conditions (Gross et al., 1969), resulting in a better confined plasma.

\subsubsection{Troubleshooting Actions}

At an OCV of 160 volts, the AIRCO power supply in use in the present study is designed to operate at voltage levels of up to 80 volts. Since we were attempting to operate a methane plasma at $28 \mathrm{l} / \mathrm{min}(1 \mathrm{cfm})$, the voltage requirement is presumably higher than 80 volts because an argon arc discharge extinguishes upon introduction of methane. We then tried an exploratory run with a lower gas flowrate. An $80 \%$ argon $-20 \%$ methane plasma at flowrate of about 10 
$1 /$ min was successfully run for about a minute before the arc extinguished. However, the entire tungsten cathode tip was consumed in that short run time. Running at such a low flowrate would thus presumably have the problem of overheating the electrodes. Thus, it was deemed better to run at higher flowrates and seek appropriate means to provide the higher operating voltages.

Previous attempts to run with an argon plasma under a 320-volt OCV power supply configuration, also available on our power supply, resulted in the blow-out of a switchbox fuse or the tripping of the main circuit breaker. This occurred because the input electrical feed lines to the power supply are rated only for operation under the 160 -volt OCV configuration. The electrical feed lines were then upgraded during the reporting period to enable increasing the load voltage from 80 volts up to 160 volts. Under the new OCV configuration, a test-run with an argon plasma was initiated. We found out, however, that at minimum current setting, the argon arc was operating at a current of $600 \mathrm{~A}$, when the same setting was giving only $200 \mathrm{~A}$ under the $160 \mathrm{OCV}$ configuration.

Under the second approach, a solenoid was fabricated in December based on Kim's (1977) design by winding 4 layers of No. 15 enamel-coated copper wire over an 8" section of a 9" long bakelite tube 15.5" O.D. by 14.5" I.D., which is wide enough to clear the fittings and enclose the entire plasma reactor. The number of turns per layer is approximately 130 . The solenoid was installed onto the reactor and connected to a 400 watt d.c. power supply. The four coils were connected in parallel and the resistance of the solenoid was measured to be $0.7 \mathrm{ohm}$. Based on an interelectrode gap of 1/8" and arc voltages of $60-120$ volts, the calculated magnetic field strength required for arc rotation is $80-120$ gauss.

In January, magnetic field measurements were made with a Bell 610 Gaussmeter, kindly loaned to our group by the MIT Plasma Fusion Center. At a total solenoid current of $15 \mathrm{~A}$, the measured axial magnetic field varied from only 43 gauss at the base of the anode insert to 77 gauss at the top of the anode insert. The presence of the steel flange and cooling chamber significantly altered the magnetic field strength at the center of the reactor. In order to have a stronger magnetic field, four more coils were installed on the solenoid for a total of eight in January. These eight coils were divided into four segments each consisting of two coils connected in series. The four two-coils-in-series segments were then connected in parallel. This configuration gave a total solenoid resistance of $0.9 \mathrm{ohm}$, which is optimum for maximizing the $20 \mathrm{v} / 25$ A capacity of the solenoid power supply.

Magnetic field measurements were taken in February on the stronger field strength solenoid. At a total current of $20.6 \mathrm{~A}$, the measured axial magnetic field varied from 118 gauss at the base (Db, Figure 1) of the anode insert to 195 gauss at the top (Dt, Figure 1) of the anode insert (D, Figure 1), which is sufficient for arc rotation.

Under the 320-volt OCV power supply configuration and with the stronger field strength solenoid, a series of test-firing runs of the plasma reactor was then performed. The first of these tests revealed that the two approaches taken were effective in making a $100 \%$ methane plasma run possible. From a $1 \mathrm{cfm}$ (ambient temperature) argon plasma, we were able to change over to a $1 \mathrm{cfm}$ (ambient temperature) $100 \%$ methane plasma. Power input to the methane plasma was, 
however, turned off rightaway for fear of melting the electrodes. The transition time was about 1 minute. The voltage was about 80-85 v and the current fluctuated between 250-350 A towards the end of the run. Upon disassembly, the initially 1-inch long by $1 / 4$ " diameter tungsten cathode (H, Figure 1) was shorter by more than $1 / 2$ ". Tungsten metal was found deposited on the anode insert D (Figure 1), at the bottom of the cooling chamber and even on the alumina gas injector shield I (Figure 1). The anode insert was slightly eroded.

To minimize the consumption of the tungsten electrode, the tip was pulled up so that only $1 / 8$ " was inserted into the anode insert instead of $3 / 4 "$. The changeover from argon to methane was made in about a minute again. When disassembled, a significant portion of the tip was again consumed, though not as much as in the first test.

Because the tungsten cathode tip is not likely to survive a methane plasma for more than a few seconds, the next test used a graphite cathode tip of the same geometry. Even before attempting to switch to methane, the graphite tip was tested under a $1 \mathrm{cfm}$ argon plasma at 600 A, the minimum current setting under the new OCV power supply configuration. The problem encountered this time was that the graphite cathode was severely eroded in argon presumably because of the high current density. To counter this effect, it was decided to use a graphite-tipped cathode with a larger tip area. However, this necessitated redesign of the plasma reactor.

The next generation plasma reactor which was constructed in February is schematically shown in Figure 2. A water-cooled brass anode holder B mounts onto the top flange A. A threaded graphite anode $\mathrm{C}$ is screwed into the brass anode holder $\mathrm{B}$. The graphite anode $\mathrm{C}$ has a 1-inch I.D. The upper portion of the graphite anode $C$ is electrically insulated with a ring of boron nitride $\mathrm{D}$. The cathode assembly consists of a nylon piece $\mathrm{E}$, which serves as mounting body for the water-cooled copper cathode $\mathrm{F}$. This nylon piece also helps electrically insulate the anode from the cathode and is secured to the brass anode holder B and to the top steel flange A with three screws. A low-density alumina ring $\mathrm{G}$ thermally insulates the nylon body $\mathrm{E}$ from the graphite anode $\mathrm{C}$. A high-density alumina tube $\mathrm{H}$ thermally insulates $\mathrm{E}$ from arc radiation. The cathode tip I is a 3/4" O.D. by 2 inches long graphite rod, axially based and tapped so that it can be attached to the threaded bottom end of the copper section of the cathode F. Gas or gas plus entrained powder is introduced in the $1 / 8$ " annular space between the cathode $\mathrm{F}$ and anode $\mathrm{C}$.

The new reactor was subjected to a series of tests, with the electrodes being disassembled and replaced after each run. The first two tests were under a $1 \mathrm{cfm}$ (ambient temperature) argon plasma at the minimum current of $600 \mathrm{~A}$. These tests revealed minimal erosion of the cathode tip for run times of 30 seconds and of 90 seconds. The next test involved changing over to a $1 \mathrm{cfm}$ (ambient temperature) 100\% methane plasma. The transition lasted about 4 minutes with the voltage averaging around 130 volts and the current fluctuating around $400 \pm 50$ amperes towards the end of the run. A $100 \%$ methane plasma was sustained for about 10 to 15 seconds only since we wanted to be extremely cautious about not consuming the entire electrode and risking a burn-out. Upon disassembly, the cathode tip was basically intact, still about 2 inches long, but the bottom half inch seemed to have melted and then solidified. The anode nozzle (lower portion 
of C, Figure 2) had deposits at the outlet. The I.D. of the anode seemed to be enlarged and the texture changed to a shiny constituency.

\subsubsection{Scoping Runs with Methane and Magnesium Oxide}

The results from the series of scoping runs with $\mathrm{CH}_{4} / \mathrm{MgO}$ are presented here.

\subsubsection{Scoping Run No. SR-CM-1: Methane Plasma Established before MgO Feeding}

After the three tests, we were confident that the new design was suitable for running a methane plasma over a period of a few minutes. We then went on to carry out a $\mathrm{MgO} / \mathrm{CH}_{4}$ scoping run. From a $1 \mathrm{cfm}$ argon plasma, a 100\% $1 \mathrm{cfm}$ methane plasma was established within 2 minutes. The voltage was varying between $85-90 \mathrm{v}$ and the current was fluctuating widely around $350 \mathrm{~A}$ under the methane plasma. $\mathrm{MgO}$ feeding at $6 \mathrm{~g} / \mathrm{min}$ was initiated shortly after the methane plasma was established and was sustained for about a minute. Upon powder feeding, both voltage and current started to fluctuate greatly such that taking a reading proved to be very difficult. The voltage ranged between 85 to 120 volts while the current ranged between 300 to $400 \mathrm{~A}$. Total system pressure in the cooling chamber also went up to as much as $12 \mathrm{psi}$ due to clogging of the filters in the products collection train.

When the reactor was disassembled, the cathode tip was again found to be intact with indications of melting and then solidification. GC analysis of the headspace above unhydrolyzed and hydrolyzed solid samples collected from this run both revealed the presence of $\mathrm{C}_{3} \mathrm{H}_{4}$ and $\mathrm{C}_{2} \mathrm{H}_{2}$. If $\mathrm{C}_{3} \mathrm{H}_{4}$ and $\mathrm{C}_{2} \mathrm{H}_{2}$ had been detected only after hydrolysis of the collected solids, it would be a strong indication that $\mathrm{Mg}_{2} \mathrm{C}_{3}$ (which hydrolyzes to $\mathrm{C}_{3} \mathrm{H}_{4}$ ) and $\mathrm{MgC}_{2}$ (which hydrolyzes to $\mathrm{C}_{2} \mathrm{H}_{2}$ ) were formed. Since these acetylenes were detected with and without hydrolysis, we could not prove that magnesium carbides were formed. If indeed they were formed, the quantities must have been very small. By feeding $\mathrm{MgO}$ only after a $100 \%$ methane plasma was established and then sustained for a few seconds, methane was in stoichiometric excess, as evidenced by significant soot formation.

In March, a series of scoping runs was performed under a different approach in which the $\mathrm{MgO}$ was in stoichiometric excess. Instead of sustaining a $100 \%$ methane plasma first, $\mathrm{MgO}$ was fed in an argon plasma prior to the introduction of methane. Switching from argon to methane was done when the desired $\mathrm{MgO}$ feedrate was achieved.

\subsubsection{Scoping Run No. SR-M-1: MgO Feeding Before Establishing Methane Plasma ("Breakthrough" Run)}

In the first scoping run under this new approach, a $1 \mathrm{cfm}$ (ambient temperature) argon plasma was established. $\mathrm{MgO}$ feeding at $12 \mathrm{~g} / \mathrm{min}$ was initiated 30 seconds later. Shortly thereafter, the argon was slowly replaced with methane. The switchover to methane was complete at 2 minutes and 45 seconds after initiation of the argon plasma. Power to the arc was 
turned off a few seconds later. The pressure in the cooling chamber rose above $1000 \mathrm{~mm} \mathrm{Hg}$ upon initiation of the argon plasma and attempts to control it at below $1 \mathrm{~atm}$ proved futile. The arc voltage and current were fluctuating greatly such that taking a reading proved to be very difficult. The voltage seemed to average around 130 volts, ranging between 125 to 135 volts, while the current ranged between 200 and $400 \mathrm{~A}$.

Upon disassembly of the reactor, the 3/4" O.D. graphite cathode tip was found to be intact with indications of melting and then solidification. A small amount of solids was collected in a sampler downstream of the probe while the majority of the solids was deposited on the sintered stainless steel disc at the bottom of the cooling chamber.

GC analysis of the headspace above both unhydrolyzed and hydrolyzed solid samples collected from this run also revealed the presence of significant quantities of $\mathrm{C}_{3} \mathrm{H}_{4}$ and $\mathrm{C}_{2} \mathrm{H}_{2}$, i.e. in percentage, not ppm, levels. In addition to $\mathrm{C}_{3} \mathrm{H}_{4}$ and $\mathrm{C}_{2} \mathrm{H}_{2}$, which together, comprised more than $90 \%$ of the gas sample, various other hydrocarbons such as $\mathrm{CH}_{4}, \mathrm{C}_{3} \mathrm{H}_{8}, \mathrm{C}_{3} \mathrm{H}_{6}, \mathrm{C}_{2} \mathrm{H}_{4}, \mathrm{C}_{2} \mathrm{H}_{6}$, and $\mathrm{C}_{4}$ 's were detected. However, in contrast to the scoping run done in February, significant bubble formation accompanied by a distinct smell was observed upon hydrolysis of the solid samples. To test the hypotheses that other hydrocarbons are methane pyrolysis products and that they were carried out of the reactor adsorbed onto the carbides or soot particles, the solid samples were subjected to various kinds of treatment including heating, vacuum degassing and combinations thereof. Table 1 summarizes the results of the $\mathrm{GC}$ analyses of the headspace above these samples.

No quantification of the carbide yield was done in this study because the sampling was done cumulatively, i.e. sampling was done throughout the entire run. In what is envisioned to be a better-controlled experimental run, sampling will be performed only when fully developed flows of methane and $\mathrm{MgO}$ are established. Nevertheless, the study provided several insights. First, the observation of bubble formation on hydrolysis is a strong indication of the formation of magnesium carbides. Figures 3 and 4, which are the GC analyses of the headspace above preand post-hydrolysis solid samples, respectively, show strong increases in hydrocarbon formation after hydrolysis. Second, heat treatment of the solid samples seems to increase the yield of $\mathrm{C}_{3} \mathrm{H}_{4}$ relative to $\mathrm{C}_{2} \mathrm{H}_{2}$, which suggests that $\mathrm{MgC}_{2}$ (which hydrolyzes to $\mathrm{C}_{2} \mathrm{H}_{2}$ ) is being converted to $\mathrm{Mg}_{2} \mathrm{C}_{3}$ (which hydrolyzes to $\mathrm{C}_{3} \mathrm{H}_{4}$ ) upon heating. Third, although $\mathrm{C}_{3} \mathrm{H}_{4}$ and $\mathrm{C}_{2} \mathrm{H}_{2}$ are the major gaseous products of hydrolysis, the detection of other hydrocarbons upon hydrolysis may be indicative of other hydrolysis reactions taking place or of desorption of hydrocarbons generated earlier by methane pyrolysis. The latter could arise by displacement of hydrocarbons sorbed on soot or carbide surfaces, or by release of trapped $\mathrm{HC}$ due to disintegration of the carbides during chemical reaction. 
Table 1. Summary of GC Analyses of Headspace above Solid Samples

\begin{tabular}{|c|c|c|c|c|c|}
\hline $\begin{array}{l}\text { Source of } \\
\text { Sample }\end{array}$ & $\begin{array}{l}\text { Treatment of Solid } \\
\text { Before Hydrolysis }\end{array}$ & Hydrolysis ${ }^{\mathrm{a}}$ & $\begin{array}{c}\text { Amount of } \\
\mathrm{HC}^{\mathrm{b}}\end{array}$ & $\begin{array}{c}\% \mathrm{C}_{3} \mathrm{H}_{4}+ \\
\mathrm{C}_{2} \mathrm{H}_{2}\end{array}$ & $\begin{array}{c}\mathrm{C}_{3} \mathrm{H}_{4}: \mathrm{C}_{2} \mathrm{H}_{2} \\
\text { Ratio }\end{array}$ \\
\hline $\begin{array}{l}\text { Downstream } \\
\text { Probe }\end{array}$ & None & Yes & + & 96 & $1: 2$ \\
\hline \begin{tabular}{c|} 
Cooling \\
Chamber Bottom
\end{tabular} & $\begin{array}{c}\text { Heated to } 100^{\circ} \mathrm{C} \text { for } 5 \\
\text { min }\end{array}$ & No & + & 95 & $1: 2$ \\
\hline \begin{tabular}{|c|} 
Cooling \\
Chamber Bottom
\end{tabular} & $\begin{array}{c}\text { Heated to } 100^{\circ} \mathrm{C} \text { for } 5 \\
\text { min; Vacuum degassed } \\
\text { @ ambient T }\end{array}$ & No & - & 78 & $1.5: 1$ \\
\hline \begin{tabular}{|c|} 
Cooling \\
Chamber Bottom
\end{tabular} & $\begin{array}{c}\text { Heated to } 100^{\circ} \mathrm{C} \text { for } 5 \\
\text { min; Vacuum degassed } \\
@ \text { ambient T }\end{array}$ & Yes & + & 87 & $1.5: 1$ \\
\hline \begin{tabular}{|c|} 
Cooling \\
Chamber Bottom
\end{tabular} & $\begin{array}{c}\text { Vacuum degassed @ } \\
\text { ambient T }\end{array}$ & No & - & 89 & $1: 1$ \\
\hline \begin{tabular}{c|} 
Cooling \\
Chamber Bottom
\end{tabular} & $\begin{array}{c}\text { Vacuum degassed @ } \\
\text { ambient T }\end{array}$ & Yes & + & c & $1: 1$ \\
\hline \begin{tabular}{|c|} 
Cooling \\
Chamber Bottom
\end{tabular} & $\begin{array}{l}\text { Vacuum degassed @ } \\
120^{\circ} \mathrm{C} \text { overnight }\end{array}$ & No & - & c & c \\
\hline $\begin{array}{c}\text { Cooling } \\
\text { Chamber Bottom }\end{array}$ & $\begin{array}{l}\text { Vacuum degassed @ } \\
120^{\circ} \mathrm{C} \text { overnight; heated } \\
\text { to } 100^{\circ} \mathrm{C} \text { for } 10 \mathrm{~min}\end{array}$ & No & - & 77 & $1: 3$ \\
\hline $\begin{array}{c}\text { Cooling } \\
\text { Chamber Bottom }\end{array}$ & $\begin{array}{l}\text { Vacuum degassed @ } \\
120^{\circ} \mathrm{C} \text { overnight; heated } \\
\text { to } 100^{\circ} \mathrm{C} \text { for } 10 \mathrm{~min}\end{array}$ & Yes & + & 74 & $3: 1$ \\
\hline
\end{tabular}

${ }^{a}$ Bubbling was visible in all hydrolysis cases.

${ }^{\mathrm{b}}$ Amount of Hydrocarbons detected: (+) significant; (-) minimal.

${ }^{c}$ Data not available.

Because detection of acetylenes from hydrolysis of the solid products is an indirect method of carbide identification, X-ray diffraction analysis was performed as a direct identification technique. Figure 5 shows the $\mathrm{X}$-ray diffraction pattern of the solid sample from the bottom of the cooling chamber, which reveals three peaks matching the pattern for $\mathrm{MgC}_{2}$ and two peaks for $\mathrm{Mg}_{2} \mathrm{C}_{3}$. Although the complete diffraction patterns for $\mathrm{MgC}_{2}$ and $\mathrm{Mg}_{2} \mathrm{C}_{3}$ show several other peaks, the absence of these in the present specimens may reflect the small size of the crystals in the sample.

\subsubsection{Scoping Run No. SR-AM-1: Blank Ar/MgO Run (without Methane)}

The graphite electrodes used in the scoping run were only prototypes, which were specifically fabricated for the trial run. Having demonstrated the feasibility of the basic design, 
modifications were conceived to allow for easy replacement of the electrodes after each run. In particular, the modified design called for a 1.5" I.D., 1.5" deep counterbore in the graphite anode to allow insertion of a 1.5" O.D. / 1" I.D. graphite ring which will serve as an anode insert. In a trial run using this modified electrode, a $1 \mathrm{cfm}$ (ambient temperature) argon plasma was initiated and $\mathrm{MgO}$ was fed at $12 \mathrm{~g} / \mathrm{min}$ for about 2 minutes. The arc current was about $600 \mathrm{~A}$ and the voltage was 20-25 volts. The cooling chamber pressure was successfully maintained below 760 $\mathrm{mm} \mathrm{Hg}$. At the end of the run, the gray solids collected at the bottom of the cooling chamber exhibited bubbling upon hydrolysis. GC analysis of the headspace above the hydrolyzed solid sample revealed about $83 \% \mathrm{C}_{3} \mathrm{H}_{4}+\mathrm{C}_{2} \mathrm{H}_{2}$, with a $1: 1 \mathrm{C}_{3} \mathrm{H}_{4}: \mathrm{C}_{2} \mathrm{H}_{2}$ ratio. Various other hydrocarbons were detected as well. However, the amount of hydrocarbons detected is lower than that in the previous $\mathrm{MgO} / \mathrm{CH}_{4}$ run. This suggests that carbon from the graphite electrodes is also reacting with $\mathrm{MgO}$ to form carbides. Thus, it will be necessary to quantify this contribution in each experiment.

\subsubsection{Scoping Run No. SR-M-2: Run with Lower Chamber Pressure Build-up}

Having maintained the pressure below $760 \mathrm{~mm} \mathrm{Hg}$ in the $\mathrm{MgO} / \mathrm{Ar}$ run, it was hypothesized that the difficulty of controlling the chamber pressure in the $\mathrm{MgO} / \mathrm{CH}_{4}$ run described above was due to clogging of the sintered stainless steel disc at the bottom of the chamber. The top $5 \mu$ disc was therefore removed, leaving only the bottom $100 \mu$ disc. A $5 \mu$ filter cartridge with a larger area was then installed downstream of the cooling chamber. With this configuration, another scoping run with $\mathrm{MgO} / \mathrm{CH}_{4}$ was performed using the graphite anode insert.

A $1 \mathrm{cfm}$ (ambient temperature) argon plasma was initiated and $12 \mathrm{~g} / \mathrm{min}$ of $\mathrm{MgO}$ were fed into the plasma 30 seconds later. The switchover to methane commenced a few seconds afterwards. Two and a half minutes after initiation of the argon plasma, the changeover to methane was complete. $\mathrm{MgO}$ feeding into the methane plasma continued for 40 seconds more. The arc voltage ranged from 80 to 100 volts and the current from 250 to $450 \mathrm{~A}$. The chamber pressure was successfully maintained below $760 \mathrm{~mm} \mathrm{Hg}$ and the temperature at the axis of the chamber about 8.5 inches below the anode nozzle exit measured with a type $\mathrm{K}$ thermocouple rose to $950^{\circ} \mathrm{C}$.

Upon withdrawal of the probe from the chamber, some solid particles dislodged from the probe instantaneously glowed upon exposure to the ambient atmosphere. When the cartridge filter was removed, the solids in the cartridge likewise glowed once exposed to the atmosphere. This strongly suggests that the solid products are carbides that reacted with moisture in the air, exothermically forming acetylenes which ignited instantaneously in the presence of oxygen and elevated temperatures arising from localized heating of the specimens. $\mathrm{GC}$ analysis of the headspace above hydrolyzed solid products revealed very little $\mathrm{CH}_{4}, \mathrm{C}_{3} \mathrm{H}_{4}$ and $\mathrm{C}_{2} \mathrm{H}_{2}$ (and no other hydrocarbon), indicating that the carbides were almost completely hydrolyzed upon exposure to the atmosphere. It should also be noted that the rapid and instantaneous reaction may be attributed to the small particle size of the carbides. The solids in the filter cartridge are 
presumably between 5 and $100 \mu$, and even smaller particles may be sorbed on these. In later experiments, particle sizes will be determined more quantitatively by electron microscopy.

\subsubsection{Upgrading of the Experimental Apparatus}

In preparation for a systematic study of carbide formation in the rotating arc reactor, graphite electrodes were fabricated in larger quantities during this reporting period. Plans for upgrading the experimental apparatus were also finalized to allow solid and gas sampling only during a period of the run time when the flows of methane and $\mathrm{MgO}$ are fully established. Solenoid valves to be used for this purpose were sized and ordered. An order was also placed for an automatic pressure controller necessary to maintain the chamber pressure at 1 atm. Specifications for a data acquisition system are likewise being drawn up so that arc voltage and current can be recorded on a computer. The same system will be used for timed output signals to actuate the solenoid valves.

\section{Progress on Task 2: Mechanistic Foundations for Converting Light Hydrocarbon Gases to Metal Carbides, Hydrogen and Carbon Monoxide}

Aside from the GC study and X-ray diffraction work, a High Pressure Liquid Chromatography (HPLC) analysis performed on toluene extracts of solid particle deposits recovered from the anode nozzles used in the earlier methane stabilization test runs as well as in the $\mathrm{MgO} / \mathrm{CH}_{4}$ scoping runs revealed no $\mathrm{C}-60$ or $\mathrm{C}-70$ fullerenes in the sample.

\section{Conclusions}

Based on the results of the scoping runs, there appears to be strong indications that a breakthrough has finally been achieved in that synthesis of magnesium carbides from $\mathrm{MgO}$ and methane in the arc discharge reactor has been demonstrated.

\section{Future Plans}

In the next reporting period, the pressure control system, data acquisition system and improved sampling scheme will be installed. Aside from improving characterization of the process conditions for carbide formation, analytical techniques will also be explored for investigating carbide yields and characterizing the solid product. We will begin performing systematic runs in the next period.

\section{References}

1. Blanchet, J.L., "Reactions of Carbon Vapor with Hydrogen and with Methane in a High Intensity Arc", Sc.D. Thesis, Department of Chemical Engineering, MIT, Cambridge, MA, (1963). 
2. Gross, B., B. Grycz and K. Miklossy, "Plasma Technology", American Elsevier Publishing Company, Inc., New York (1969).

3. Kim, C.S., "Formation of $\mathrm{CaC}_{2}$ from $\mathrm{CaO}$ and 'Nascent' Carbon Species in a Rotating-Arc Reactor", Sc.D. Thesis, Department of Chemical Engineering, MIT, Cambridge, MA, (1977).

4. Kim, C.S., R.F. Baddour, J.B. Howard and H.P. Meissner, " $\mathrm{CaC}_{2}$ Production from $\mathrm{CaO}$ and Coal or Hydrocarbons in a Rotating-Arc Reactor", Ind. Eng. Chem. Process Des. Dev. 18, 323-328, (1979). 


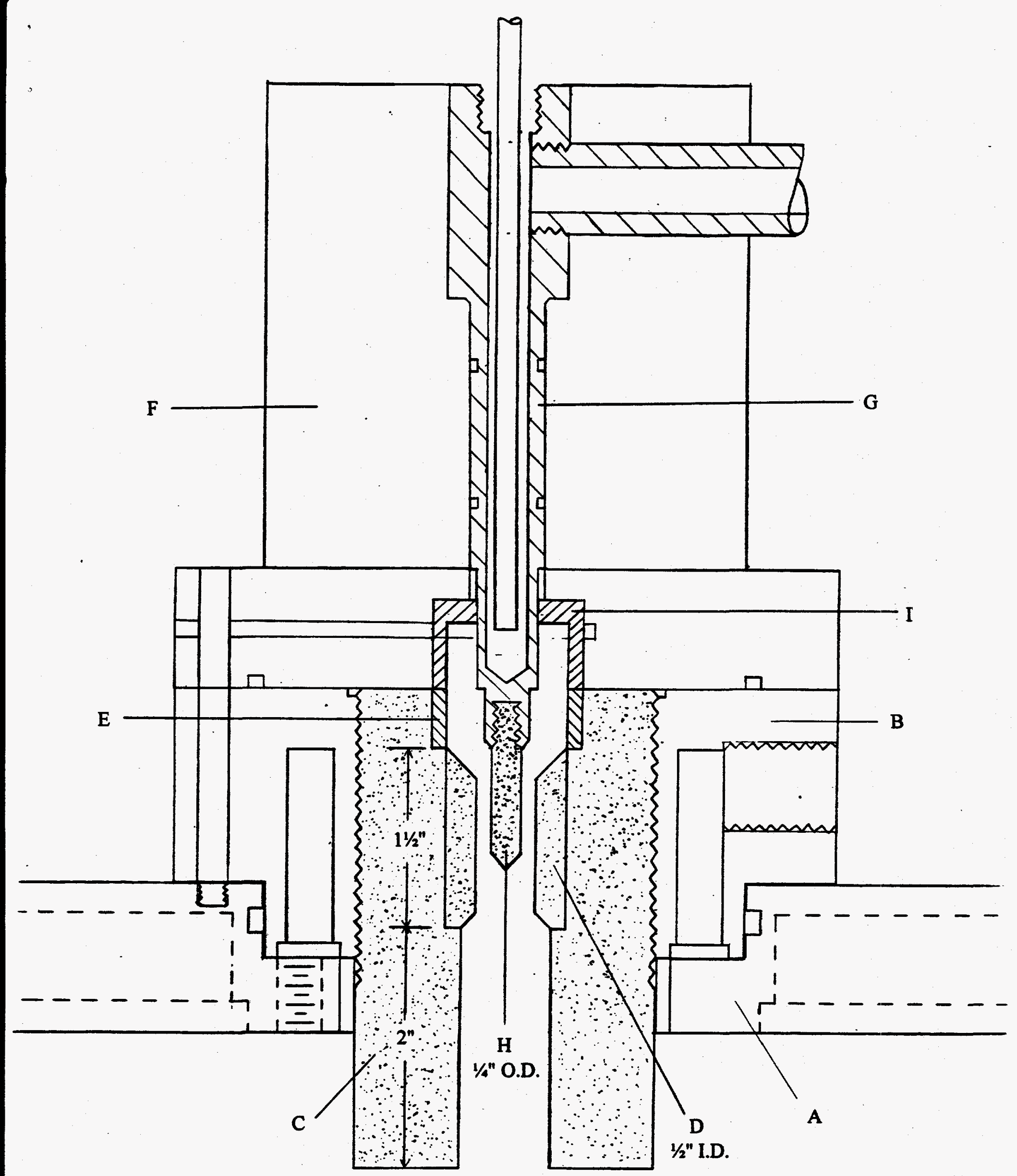

Figure 1. Schematic Representation of Plasma Reactor Assembly Used in January and February 1995 


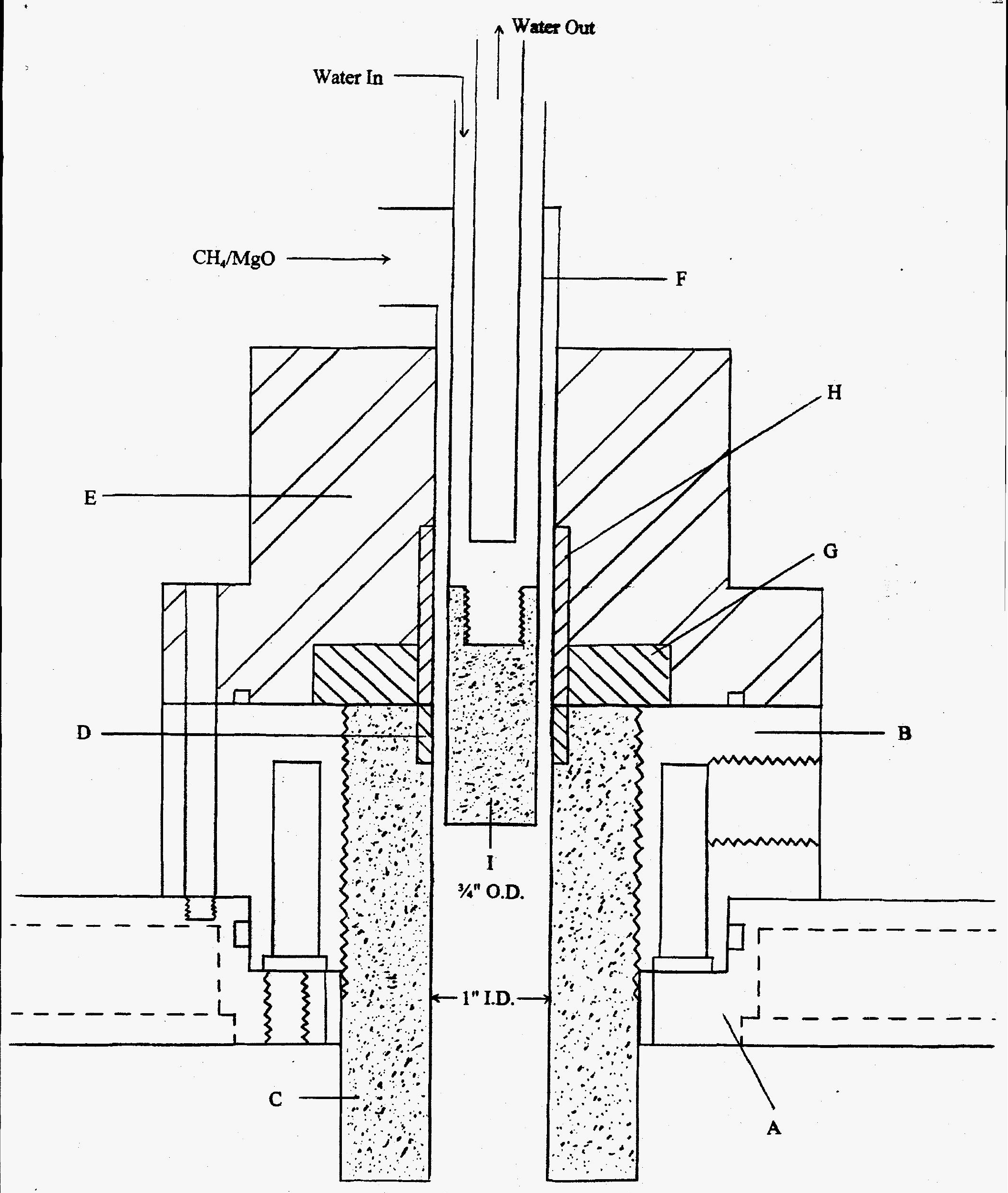

Figure 2. Schematic Representation of Redesigned Plasma Reactor Assembly 
Figure 3. GC Analysis of Headspace Above Unhydrolyzed Solid Sample Heated to $100^{\circ} \mathrm{C}$ for $5 \mathrm{~min}$; Vacuum degassed @ Ambient T

$0.5 \mathrm{ml}$ Sample Gas Injection

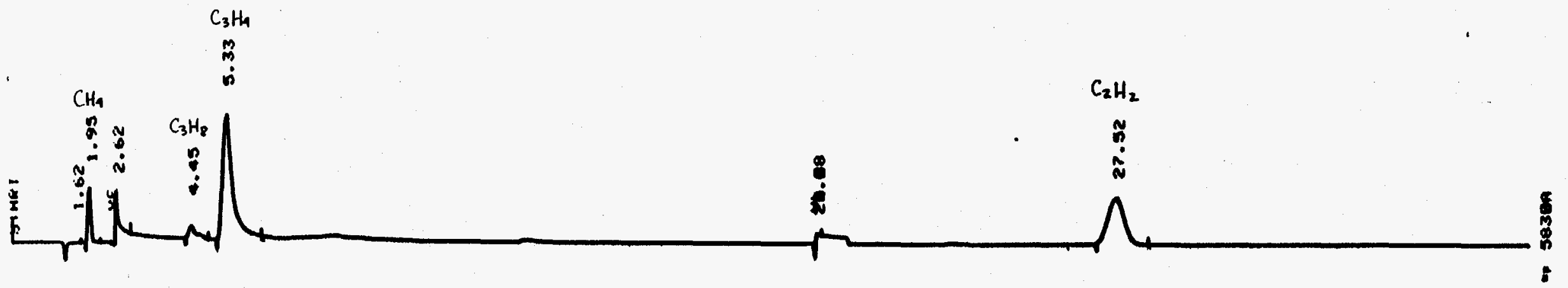



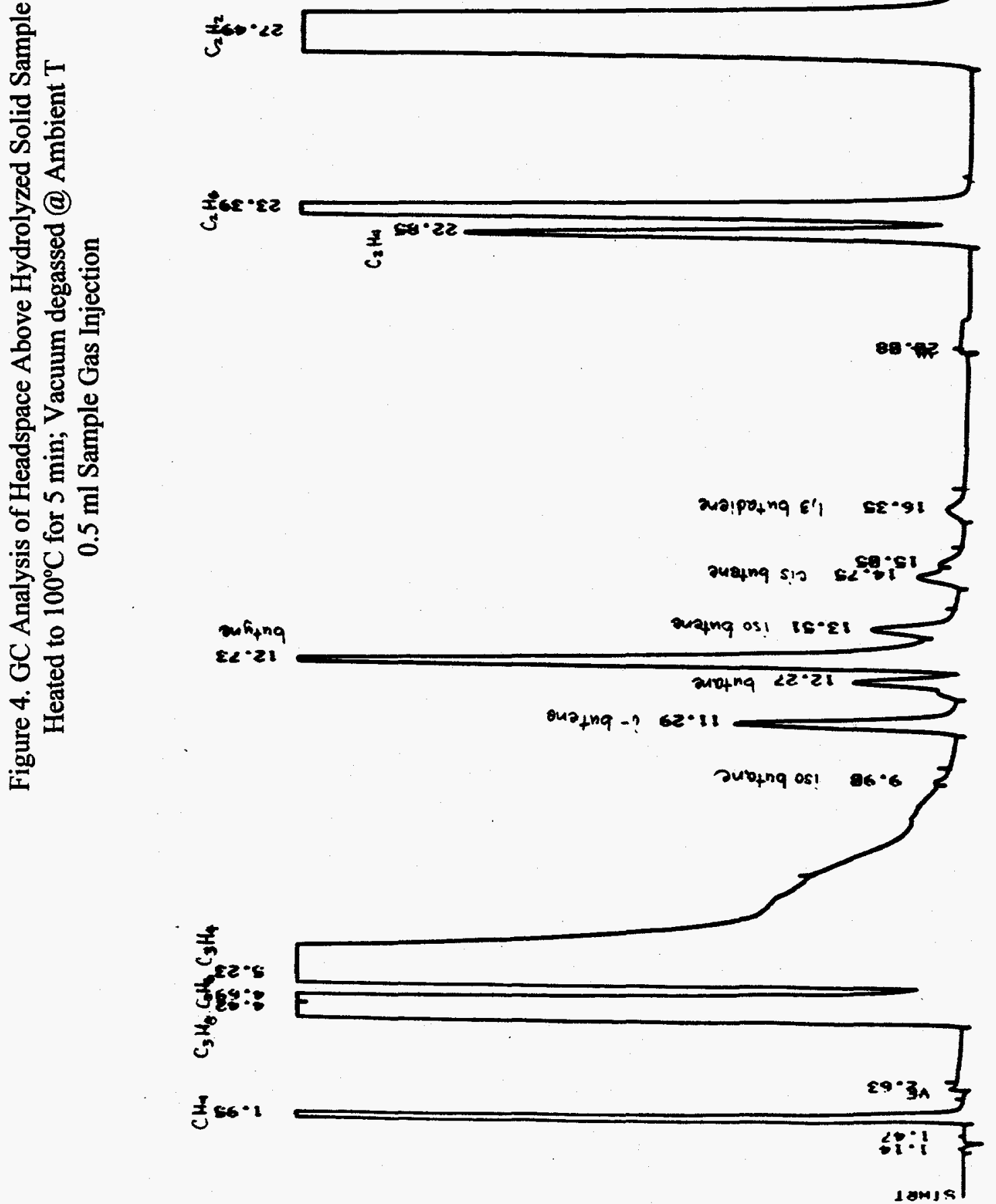
Figure 5. X-ray Diffraction Pattern of Solid Sample From Chamber Bottom

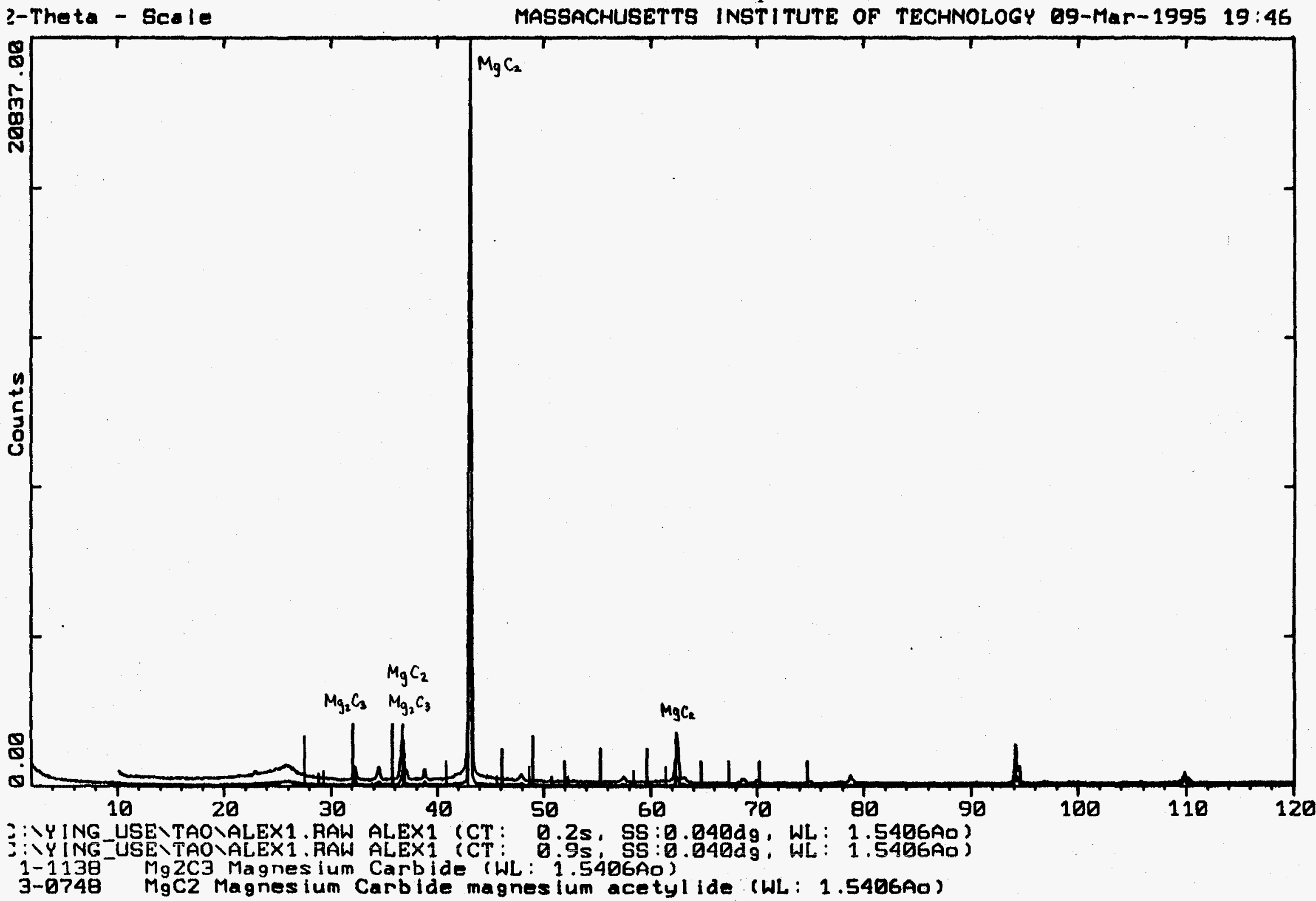

